\title{
Toxigenic Corynebacterium ulcerans in a fatal human case and her feline contacts, France, March 2014
}

\author{
S Vandentorren (stephanie.vandentorren@ars.sante.fr) ${ }^{1}, \mathbf{N}$ Guiso ${ }^{2}$, E Badell ${ }^{2}$, P Boisrenoult ${ }^{3}$, M Micaelo $^{4}$, G Troché5, P Lecouls 6 , \\ M J Moquet ${ }^{7}$, 0 Patey $^{8}$, E Belchior ${ }^{9}$ \\ 1. Regional office of the French Institute for Public Health Surveillance - Ile de France and Champagne Ardenne, Paris, France \\ 2. Institut Pasteur, National reference centre for Corynebacteria of the diphtheria complex, Paris, France \\ 3. Department of orthopaedic and trauma surgery, Central Hospital of Versailles, Versailles, France \\ 4. Department of Microbiology, Central Hospital of Versailles, Versailles, France \\ 5. Department of Medical-surgical reanimation, Central Hospital of Versailles, Versailles, France \\ 6. Direction for the protection of populations of Yvelines, Versailles, France \\ 7. Regional Health Agency of Ile de France, Paris, France \\ 8. Intermunicipal Central Hospital, Villeneuve-Saint-Georges, France \\ 9. Department of infectious diseases, French Institute for Public Health Surveillance, Saint-Maurice, France
}

Citation style for this article:

Vandentorren S, Guiso N, Badell E, Boisrenoult P, Micaelo M, Troché G, Lecouls P, Moquet MJ, Patey O, Belchior E. Toxigenic Corynebacterium ulcerans in a fatal human case and her feline contacts, France, March 2014. Euro Surveill. 2014;19(38):pii=20910. Available online: http://www.eurosurveillance.org/ViewArticle. aspx?Articleld $=20910$

Article submitted on 14 September 2014 / published on 11 September 2014

In March 2014, a person in their eighties who was diagnosed with extensive cellulitis due to toxigenic Corynebacterium ulcerans died from multiple organ failure. Environmental investigation also isolated $C$. ulcerans in biological samples from two stray cats in contact with the case. This finding provides further evidence that pets can carry toxigenic $C$. ulcerans and may be a source of the infection in humans.

In March 2014, the French Institute for Public Health Surveillance (Institut de Veille Sanitaire, InVS) was informed that a toxigenic Corynebacterium ulcerans had been isolated from soft tissue samples of a patient in their eighties with extensive cellulitis in their hand and arm. The patient had received a diphtheria vaccination booster in October 2003. It is not known whether this patient received at least three doses of a combined diphtheria, tetanus and polio (DTPolio) vaccine in childhood. After the onset of symptoms, the patient attended a hospital emergency department because of sepsis (hyperthermia and inflammation) and cellulitis.

C. ulcerans was not isolated from the surgical subcutaneous swab of the patient's right hand taken at admission on Day o. Three blood cultures, performed on Day o in Bact/Alert bottles (BioMérieux) were also negative after five days incubation at $35^{\circ} \mathrm{C}$. Both aerobic and anaerobic cultures were performed. In addition, three soft tissue samples from the patient's right hand, taken during surgery on Day 2, were cultured on sheep blood agar and chocolate agar. All were positive for $C$. ulcerans, identified using MALDI-TOF [1]. No other bacteria except $C$. ulcerans (present in pure culture) were isolated from the three soft tissue samples.

Intravenous antibiotic treatment was initiated with amoxicillin and clavulanic acid on Day 0 and complemented on Day 1 with gentamicin. The patient was admitted into the intensive care unit as they presented signs of systemic infection with multiple organ failure on Day 3 (thrombocytopenia, renal failure, and arrhythmia). Antibiotic treatment was changed to clindamycin, piperacillin and tazobactam. Ventricular arrhythmia and cardiac failure occurred. The patient died on Day 6.

\section{Microbiological investigation}

One culture from each of the three soft tissue samples was sent to the National Reference Centre (NRC) and the identification of $C$. ulcerans was confirmed by a multiplex PCR [2]. The NRC detected the presence of the tox gene by end-point PCR [3] and the production of diphtheria toxin by the isolate using the modified Elek test [4]. The isolate was sensitive to a large spectrum of antibiotics (among others: penicillin, amoxicillin, gentamicin, erythromycin, clindamycin, azithromycin, cotrimoxazole, ciprofloxacin) but not fosfomycine. Multilocus sequence typing (MLST) was performed using the MLST methodology used for C. diphtheria [5].

\section{Veterinary investigation}

A follow-up investigation was conducted by the local health authorities. Two delivery drivers were identified who had been in close vicinity to the patient, but they were not considered as close enough contacts to be sampled. The patient had two pet cats and was taking care of three stray cats. At the end of March, all five cats were taken away by the veterinary services. Throat and ocular samples were taken from each animal. In addition, conjunctival swabs were systematically taken, even if the cats were asymptomatic. One of the stray cats had a wound on its neck which was also sampled. 
The samples were sent to the NRC for culture. C. ulcerans carrying the tox gene was isolated from the ocular sample of the stray cat with the wound and from the throat sample of another stray cat. The isolates were characterised using the same methods used for the human isolate. The modified Elek test was positive for both isolates. The samples of the third stray cat and the two pet cats tested negative for $C$. ulcerans.

After the patient's death, the cats were taken to an animal shelter. The Direction for the protection of populations of Yvelines decided to start antibiotics treatment of the infected cats. They were treated with amoxicillin for 10 days and a post-treatment sampling control was performed. These cultures showed the persistence of a $C$. ulcerans bearing the tox gene in the pharynx of one infected cat despite antibiotic treatment. The other post-treatment cultures were negative, including those for the cat that previously had $C$. ulcerans isolated from an ocular sample.

\section{Discussion}

From 2002 to 2013, 28 autochthonous cases of diphtheria due to toxigenic $C$. ulcerans were reported in mainland France [6]. The affected patients were mostly women (18/28) over 60 years of age with comorbidity [6]. The vaccination status was known for only six cases, and only two had received a diphtheria booster in the 20 years before the event. In veterinary investigations performed on pets owned by 14 cases only two dogs tested positive for toxigenic C. ulcerans (tox+), one of them carrying an identical ribotype as the $C$. ulcerans isolated from the owner of one of these dogs [7].

For the present case, seven housekeeping genes were compared by MLST, and all alleles from the human and animal isolates were found to be identical and belonged to sequence type ST325. This number is deduced from the $C$. diphtheriae database (http://pubmlst.org/cdiphtheriae/) and only provisional because there is presently no MLST scheme for C. ulcerans.

Nevertheless, this result strongly suggests that transmission of $C$. ulcerans tox+occurred from a stray cat. Few studies have described toxigenic $C$. ulcerans in domestic cats [8-10]. Transmission from animal to human or from a common unknown source of infection cannot be formally ruled out as several recent studies have mentioned $C$. ulcerans carriage in different mammalian species $[11,12]$.

\section{Conclusion}

The clinical course of events (sepsis and multiple organ failure) and the possible zoonotic transmission suggest that the infection by $C$. ulcerans probably led to the death of the patient. The discovery of the bacteria in the stray cats reinforces the need to strengthen the links between animal and human health research, to better characterise the circulation of the bacteria in animals. Despite national recommendations on the use of diphtheria antitoxin and vaccination boosters, severe and lethal infections due to $C$. ulcerans tox+ have been observed in France among elderly people who were in contact with cats and dogs [13].

\section{Acknowledgements}

The authors are grateful to Daniel Lévy-Bruhl, Beatrice Pangon, Constance Lebas, Juan Vinas, Mireille Billet, Catherine Vogeleisen, Agnes Giraud, Florence Collemare, Lyderic Aubert, Christiane Bruel, Celine Legout and Jourdain de Muizon.

\section{Conflict of interest}

None declared.

Authors' contributions

All the authors contributed to the acquisition of data, analysis or interpretation; drafting the paper (or revising it critically) and approve the final version.

References

1. Farfour E, Leto J, Barritault M, Barberis C, Meyer J, Dauphin $B$, et al. Evaluation of the Andromas matrix-assisted laser desorption ionization-time of flight mass spectrometry system for identification of aerobically growing Gram-positive bacilli. J Clin Microbiol. 2012;50(8):2702-7. http://dx.doi.org/10.1128/ JCM.00368-12

2. Pacheco LG, Pena RR, Castro TL, Dorella FA, Bahia RC, Carminati R, et al. Multiplex PCR assay for identification of Corynebacterium pseudotuberculosis from pure cultures and for rapid detection of this pathogen in clinical samples. J Med Microbiol. 2007;56(Pt 4):480-6. http://dx.doi.org/10.1099/ jmm.0.46997-0

3. Hauser D, Popoff MR, Kiredjian M, Boquet P, Bimet F. Polymerase chain reaction assay for diagnosis of potentially toxinogenic Corynebacterium diphtheriae strains: correlation with ADP-ribosylation activity assay. J Clin Microbiol. 1993;31(10):2720-3.

4. Engler KH, Glushkevich T, Mazurova IK, George RC, Efstratiou A. A modified Elek test for detection of toxigenic corynebacteria in the diagnostic laboratory. J Clin Microbiol. 1997;35(2):495-8.

5. Bolt F, Cassiday P, Tondella ML, Dezoysa A, Efstratiou A, Sing $A$, et al. Multilocus sequence typing identifies evidence for recombination and two distinct lineages of Corynebacterium diphtheriae. J Clin Microbiol. 2010;48(11):4177-85. http:// dx.doi.org/10.1128/JCM.00274-10

6. Institut de Veille Sanitaire (InVS). Diphtérie: données épidémiologiques. [Diphtheria: epidemiological data]. Saint Maurice: InVS. [Accessed June 2014]. French. Available from: http://www.invs.sante.fr/Dossiers-thematiques/Maladiesinfectieuses/Maladies-a-prevention-vaccinale/Diphterie/ Donnees-epidemiologiques

7. Lartigue MF, Monnet X, Le FA, Grimont PA, Benet JJ, Durrbach $A$, et al. Corynebacterium ulcerans in an immunocompromised patient with diphtheria and her dog. J Clin Microbiol. 2005;43(2):999-1001. http://dx.doi.org/10.1128/ JCM.43.2.999-1001.2005

8. De Zoysa A, Hawkey PM, Engler K, George R, Mann G, Reilly W, et al. Characterization of toxigenic Corynebacterium ulcerans strains isolated from humans and domestic cats in the United Kingdom. J Clin Microbiol. 2005;43(9):4377-81. http://dx.doi. org/10.1128/JCM.43.9.4377-4381.2005

9. Berger A, Huber I, Merbecks SS, Ehrhard I, Konrad R, Hormansdorfer S, et al. Toxigenic Corynebacterium ulcerans in woman and cat. Emerg Infect Dis. 2011;17(9):1767-9. http:// dx.doi.org/10.3201/eid1709.110391

10. Corti MA, Bloemberg GV, Borelli S, Kutzner H, Eich G, Hoelzle $\mathrm{L}$, et al. Rare human skin infection with Corynebacterium ulcerans: transmission by a domestic cat. Infection. 2012;40(5):575-8. http://dx.doi.org/10.1007/s15010-012-0254-5 
11. Schuhegger R, Schoerner C, Dlugaiczyk J, Lichtenfeld I,

Trouillier A, Zeller-Peronnet V, et al. Pigs as source for

toxigenic Corynebacterium ulcerans. Emerg Infect Dis.

2009;15(8):1314-5. http://dx.doi.org/10.3201/eid1508.081568

12. Marini RP, Cassiday PK, Venezia J, Shen Z, Buckley EM, Peters

$\mathrm{Y}$, et al. Corynebacterium ulcerans in ferrets. Emerg Infect Dis.

2014;20(1):159-61. http://dx.doi.org/10.3201/eid2001.130675

13. Bonmarin I, Guiso N, Le Fleche-Mateos A, Patey O, Patrick

$A D$, Levy-Bruhl D. Diphtheria: a zoonotic disease in France? Vaccine. 2009;27(31):4196-200. http://dx.doi.org/10.1016/j. vaccine.2009.04.048 
